\title{
PERCEPÇÃO AMBIENTAL NO ENTORNO DA UNIDADE DE CONSERVAÇÃO PARQUE ESTADUAL DAS ARAUCÁRIAS
Aline Pradeiczuk*
Arlene Renk ${ }^{* *}$ \\ $\longrightarrow$ \\ Marcos Alexandre Danieli****
}

\begin{abstract}
Resumo
Este trabalho objetiva observar a percepção do ambiente por moradores da zona de amortecimento de uma Unidade de Conservação (UC) do Oeste de Santa Catarina, o Parque Estadual das Araucárias, assim como compreender os principais problemas que os afetam, além de destacar a importância da participação desses residentes para a conservação da biodiversidade. Além disso, buscou-se, também, identificar os aspectos positivos e negativos que a Unidade de Conservação representa para essas comunidades, para que, a partir disso, possam ser tomadas ações voltadas à Educação Ambiental e realizados novos programas de conservação ambiental. Foram analisados dados sobre a unidade e $o$ ambiente com a finalidade de proporcionar ferramentas para a conservação e elementos de qualificação de planejamento e gestão. A Unidade de Conservação fica localizada entre os municípios de Galvão e São Domingos, na Bacia Hidrográfica do Rio Chapecó. Ao total foram realizadas 16 entrevistas em seis diferentes comunidades. Dos dados da pesquisa sobre a Unidade de Conservação, seis dos entrevistados já ouviram falar na palavra UC, porém dez desconhecem o termo científico da palavra. Sobre a percepção ambiental, poucos moradores souberam definir o que é ambiente, relacionando-o com a preservação. Os dados da pesquisa representam a delicada situação dessa UC, porém, é preciso compreender como as comunidades locais percebem o ambiente em que estão vivendo e quais são os problemas por eles enfrentados para que, a partir disso, a relação entre os envolvidos seja fortalecida e para que os objetivos da unidade sejam alcançados.
\end{abstract}

Palavras-chave: Avaliação. Responsabilização. Fatores extramuros. Práticas educativas.

\footnotetext{
* Acadêmica do Curso de Ciências Biológicas, Universidade Comunitária da Região de Chapecó (Unochapecó), Chapecó, Santa Catarina, Brasil. Email: aline_pra@unochapeco.edu.br.

** Doutora em Antropologia Social. Docente da Universidade Comunitária da Região de Chapecó (Unochapecó). Chapecó, Santa Catarina, Brasil. Email: arlene@unochapeco.edu.br.

*** Mestrando do Programa de Pós-Graduação em Ciências Ambientais, Universidade Comunitária da Região de Chapecó (Unochapecó). Chapecó, Santa Catarina, Brasil. Email: marcosdanieli@yahoo.com.br.
} 


\section{Introdução}

As Áreas ou Unidades de Conservação (UCs) foram criadas para minimizar a perda da biodiversidade, sendo consideradas um dos principais elementos de estratégia para a conservação da biodiversidade (RYLANDS; BRANDON, 2005). Entretanto, somente a criação das unidades não atinge a conservação dos ecossistemas se não houver uma boa relação ser humano-natureza (LUCENA, 2010). Portanto, a participação das comunidades do entorno é essencial para que os programas desenvolvidos para essas áreas sejam eficientes, considerando que essas populações desempenham um grande compromisso na conservação das áreas protegidas (BRESOLIN; ZAKRZEVSKI; MARINHO, 2010).

Em algumas categorias de Unidades de Conservação a presença de moradores em seu interior não é permitida, podendo gerar muitos embates entre a gestão e a comunidade (DIEGUES, 2001) e (MEDEIROS; IRVING; GARAY, 2004). Quem define essas categorias é o Sistema Nacional de Unidades de Conservação (SNUC), podendo elas serem públicas ou privadas. Elas podem ser de uso sustentável, permitindo a utilização da área, ou de proteção integral, onde somente o uso indireto de seus elementos naturais é aprovado (SNUC, 2006). Segundo o Cadastro Nacional de Unidades de Conservação de 2010, o Brasil possui 698 Unidades de Conservação criadas e regidas pelo Governo Federal, destas, 137 são de proteção integral e 173 de uso sustentável. Estaduais são 166 de uso sustentável e 222 de proteção integral (ZAÚ, 1998; MEDEIROS et al. 2011).

Ainda que seja visível a importância da criação dessas unidades, são notórias as discórdias e os desacordos que geralmente estão associados à insatisfação das comunidades por conta das proibições e pela perda de acesso ao espaço (DRUMOND, 2002). A percepção ambiental torna-se a chave para as análises das relações de moradores de entorno de áreas preservadas com as próprias Unidades de Conservação. Ela busca a valorização da comunicação, assim como o bom funcionamento da unidade e, fundamentalmente, a conservação da biodiversidade (PONTY, 1999). Uma das dificuldades enfrentadas pela gestão das Unidades de Conservação é a falta de envolvimento dos 
moradores da região, o que se sabe é que muitas vezes esses residentes sentem-se desmotivados e prejudicados, pois também há muita falta de informação entre a gestão e essas comunidades locais (BRESOLIN; ZAKRZEVSKI; MARINHO, 2010).

A pesquisa que originou este artigo teve como objetivos levantar a percepção dos moradores do entorno de uma Unidade de Conservação do Oeste de Santa Catarina, compreender os principais problemas que os afetam e que podem vir a causar a falta de informação sobre o uso de áreas protegidas, além de destacar a importância da participação desses residentes para a conservação da biodiversidade. Além disso, buscou-se, também, identificar os aspectos positivos e negativos que a Unidade de Conservação representa para essas comunidades para que, a partir disso, ações voltadas à Educação Ambiental possam ser tomadas e novos programas de conservação ambiental realizados.

\section{Materiais e métodos}

\section{Area de pesquisa}

A pesquisa foi desenvolvida na primeira Unidade de Conservação de araucárias gerida pelo Governo do Estado de Santa Catarina, o Parque Estadual das Araucárias (PEA) (26²7’08”S; 52॰33'56”W). Essa UC está localizada nos municípios de Galvão e São Domingos (Figura 1), na Bacia Hidrográfica do Rio Chapecó (FATMA, 2007). O Bioma da área é caracterizado por Mata Atlântica, um dos biomas mais ameaçados e com uma rica biodiversidade (DRUMMOND; FRANCO; OLIVEIRA, 2011), e por Floresta Ombrófila Mista ou Floresta de Araucária. O município de Galvão apresenta uma área territorial de $121,90 \mathrm{~km}^{2}$, com cerca de 3.472 habitantes, e o município de São Domingos possui $384,586 \mathrm{~km}^{2}$ e aproximadamente 9.491 habitantes (IBGE, 2010). 
Figura 1 - Localização do Parque Estadual das Araucárias nos municípios de São Domingos e Galvão, Estado de Santa Catarina.

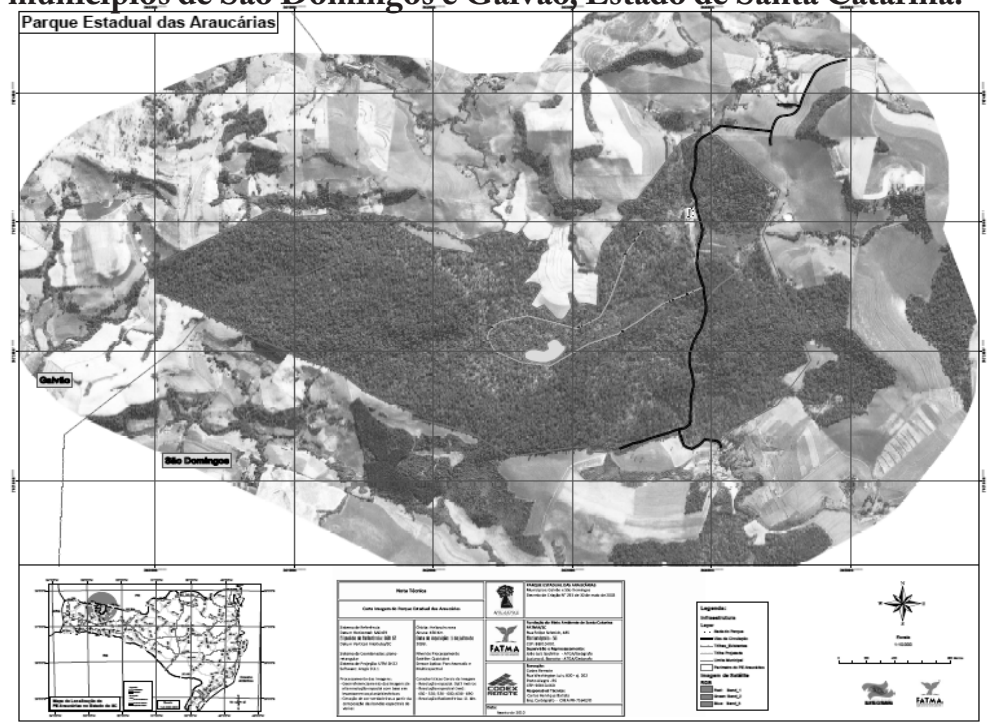

Fonte: FATMA, 2007.

Antes de ser uma UC, a área pertencia ao Sr.Jorge Berthier de Almeida. Do total da área, $4.671 .375 \mathrm{~m}^{2}$ foram adquiridos da família Hauer e $1.557 .125 \mathrm{~m}^{2}$ de um condomínio formado por moradores da cidade de Curitiba, PR (FATMA, 2007). Essa é uma das poucas UCs que contribuiu para a conservação da Floresta Ombrófila Mista, caracterizada pela espécie Araucaria angustifolia. Quanto ao corte de araucárias da área, segundo o plano de corte da Fazenda Berthier, feito pela Fundação do Meio Ambiente (FATMA), em 1989, foram registradas cerca de 11.000 unidades do pinheiro, porém destas, atualmente, restaram apenas 4.500 (FATMA, 2007).

A criação do Parque Estadual das Araucárias surgiu como uma compensação ambiental por conta da formação de um reservatório construído pela Usina Hidrelétrica Quebra Queixo, em Ipuaçu. Assim, para atender às Leis 9.985/00 e 11.986/01 e à determinação da FATMA, primeiramente, foi realizada uma consulta pública com a população de São Domingos e também de Ipuaçu dedicada a explicações e esclarecimentos.

\section{Metodologia}

Para a coleta de dados, foram utilizadas entrevistas semiestruturadas (ALEXÍADES, 1996; ALBUQUERQUE; 
LUCENA; ALENCAR, 2010) que combinam perguntas abertas

e fechadas, possibilitando ao entrevistado expressar-se mais sobre o tema e sentir-se mais à vontade para responder.

O critério para a seleção dos sujeitos entrevistados foi a partir do contato com os proprietários de áreas que pertencessem à zona de amortecimento e confrontantes com a Unidade de Conservação que residissem na propriedade ou que a frequentassem com regularidade.

As entrevistas iniciaram com perguntas voltadas ao perfil sociocultural dos moradores, logo, questões voltadas à percepção ambiental e sobre a Unidade de Conservação, para entender a relação desses habitantes com o parque e a gestão, destacando os benefícios e malefícios para quem domicilia próximo de uma área preservada. Para a análise de dados, foram feitas transcrições fieis e integrais das entrevistas gravadas e a categorização das informações coletadas.

\section{Resultados e discussões}

\section{Características dos entrevistados}

Um total de 16 entrevistas foram realizadas no entorno do Parque Estadual das Araucárias, entre os meses de maio e junho de 2013, com as comunidades: Linha Divino do município de Galvão e Manfroi; Nova Limeira; Vila Milani; Berthier e Valendorff do município de São Domingos. Todos os entrevistados são proprietários de terras confrontantes com o Parque Estadual das Araucárias. Destes, 14 residem no próprio local e dois moram no centro do município de São Domingos, mas fazem uso das terras para fins econômicos. Dos 16 moradores, 15 são agricultores, alguns já são aposentados, e um é funcionário público.

A faixa etária da população entrevistada caracterizou-se por indivíduos mais velhos, entre 37 a 64 anos. Possivelmente, o fato de a população encontrada ser fundamentalmente mais velha possa estar relacionado ao fato de os jovens estarem saindo da zona rural. A população jovem do interior tem o sonho de migrar para as cidades. Esses jovens buscam formação em instituições de ensino e a inserção no mercado de trabalho (CARNEIRO; CASTRO, 2007). Os que completam o ensino superior e voltam para a casa dos pais após finalizarem os estudos são muito poucos, pois a maioria busca emprego na área de formação ou 
constituem suas próprias famílias no meio urbano, abandonando definitivamente as atividades rurais.

Quanto às atividades desenvolvidas nas propriedades, 13 entrevistados responderam que trabalham com gado leiteiro e que é isso que sustenta suas famílias. $\mathrm{Na}$ agricultura, os principais cultivos são soja, milho e pastagens que são usadas para a alimentação do gado. Quanto ao grau de escolaridade, não há analfabetos entre eles, mas apenas um dos entrevistados cursou até o ensino médio. A maior parte desses agricultores são naturais de outras cidades, como Dionísio Cerqueira Abelardo Luz e Caçador, estes vieram para a região em busca de melhores condições de trabalho. Há, também, alguns vindos de outros estados, como Paraná e Rio Grande do Sul.

\section{Dos pontos positivos e negativos sobre a Unidade de Conservação}

De acordo com os moradores entrevistados, a Unidade de Conservação lhes trouxe mais benefícios que malefícios, como o retorno de espécies animais, águas mais protegidas e o ar aparentemente mais puro. Um dos pontos mais positivos é o fato de o parque ser uma das poucas Unidades de Conservação com bioma Mata Atlântica, além de sua importância ecológica, para a sustentabilidade, e sua função social (FATMA, 2007). Para os ambientalistas, essas áreas são de extrema importância para a conservação da biodiversidade, além de representarem um grande campo de pesquisa. Já para os moradores, as UCs podem significar coisas diferentes dependendo da classe social e cultural dessas pessoas. Assim, para que os objetivos de conservação da biodiversidade e o crescimento do desenvolvimento sustentável sejam alcançados, é necessário uma aproximação da gestão das unidades com a população local, além de um bom planejamento socioambiental e, principalmente, o envolvimento de todos os atores sociais que interessados pela causa.

Sobre a utilização de agrotóxicos nas áreas de cultivo, todos responderam que fazem o seu uso, assegurando que nos dias de hoje não existe outra possibilidade de plantio sem o uso desses agrotóxicos, conforme destacado por um dos entrevistados: "Todo mundo usa, isso não tem como esconder, isso todos usam, eu uso." Segundo o Plano de Manejo do parque, como a região é uma grande produtora de grãos, há um aumento considerável de degradação ambiental pelo uso excessivo, e muitas vezes 
impróprio, de agrotóxicos, além do uso e manejo inadequado do solo (FATMA, 2007).

No entanto, nos espaços onde são cultivados os produtos para o consumo da família, chamados de horta ou estufa, os agricultores não fazem o uso desses agrotóxicos, utilizando somente adubos orgânicos. No momento em que surgem as pragas, são utilizadas técnicas agroecológicas como a pimenta, as cinzas de madeira, a água de fumo, entre outras: "Você deixa o fumo de pacotinho na água, não lembro quantos dias. E depois mistura na água.”; "Coloca serragem, cinza do fogão, que daí gruda tudo.”.

A Mata Atlântica, que possuía uma área de $1.315 .460 \mathrm{~km}^{2}$ em 17 estados brasileiros e que abriga cerca de 20 mil espécies de plantas e aproximadamente 2.200 espécies de animais, atualmente, vive em momento crítico, pois compreende apenas $8,5 \%$ de remanescentes florestais acima de 100 hectares (SOSMA, 2010). Isso é resultado da transformação da paisagem natural desse bioma, a qual causa dificuldades para a conservação nesses pequenos espaços isolados.

A abertura de áreas na região para a agricultura no Oeste Catarinense causou muitas consequências e o que restou da vegetação foram pequenos fragmentos isolados que sofrem com alguns problemas como a caça, a presença de animais domésticos e a retirada de madeira, prejudicando a conservação da flora e fauna. A caça era considerada uma atividade tradicional de sobrevivência de muitas famílias da região, uma das formas de obter a proteína animal. Porém, por outro lado, boa parte da diminuição da fauna está associada ao processo extrativista madeireiro, visto que a população da região era empregada diretamente para trabalhar nesse tipo de atividade.

Além do embargo das construções, segundo os moradores, um aspecto considerado negativo foi o fato de a estrada que cortava o parque ter sido fechada. Para eles, o único ponto negativo foi a retirada desse caminho que servia de atalho para as comunidades: "Até quando tinha a estrada que passava por ali, quando ia pra São Domingos a gente passava. Mas depois que eles proibiram a gente nunca mais passou. $\mathrm{Na}$ verdade, nem sei como ficou aquela construção ali." Apesar disso, além de contribuir para a fragmentação do remanescente de floresta de araucária e para o potencial impacto do tráfego de veículos, a utilização dessa estrada poderia causar grandes impactos à biodiversidade que já existe no parque. 
Um caso semelhante a esse foi aprovado em abril de 2013, por uma comissão especial da Câmara Federal, em Brasília, como projeto de lei que prevê a reabertura da "Estrada/Parque" Caminho do Colono, a qual foi fechada em 2001 por determinação da justiça. A estrada tem $17 \mathrm{~km}$, passa pelo Parque Nacional do Iguaçu e liga Serranópolis do Iguaçu a Capanema, no estado do Paraná. Esse caso coloca o debate entre o desenvolvimento e o meio ambiente de uma forma figurativa, já que a construção da estrada representaria o desenvolvimento econômico e o meio ambiente representa todos aqueles hectares de Mata Atlântica com seus ecossistemas e sua biodiversidade (NASCIMENTO; BRUSZTYN, 2012).

Para a gestão do parque, a reabertura da estrada causaria muitos prejuízos à biodiversidade local. Após a área ter ficado fechada por mais de uma década, a mata nativa já retomou seu lugar, assim como a fauna. Segundo alguns políticos, será feito um levantamento do impacto socioambiental, cultural e econômico, no qual deve ser considerada a opinião dos moradores do entorno do parque (CAPANEMA, 2013).

Percebe-se que os moradores querem ver o parque realmente funcionando, visto que muitos ajudaram na construção da unidade e alguns deles demonstram interesse em participar do conselho consultivo para auxiliar na gestão e expressar suas preocupações: "É nós trabalhamos ali no parque eu e o meu cunhado [...], nós fizemos as trilhas ali, ajudamos fazer a construção lá no parque, é uma pena que está tudo parado, um dinheiro que está tudo parado, que podia estar gerando emprego, gerando renda para o município [...]”. Porém, quando a população está descontente e desestimulada, fica um pouco difícil envolvê-los para discutir soluções para o melhoramento e desenvolvimento da área.

O PEA conta com um conselho consultivo, conforme define o artigo 30 da lei do SNUC, regulamentado pelos artigos 17 a 20 do Decreto Federal n ${ }^{\circ}$ 4.340, de 22 de agosto de 2002. Esses conselhos são formados por representantes dos diversos segmentos da região interessados em auxiliar no planejamento e gestão da unidade (SNUC, 2006). A criação do conselho consultivo do Parque Estadual das Araucárias foi no ano de 2008, composto por instituições governamentais e sociais que atuam na região do parque (APREMAVI, 2012). A Constituição Federal de 1988 traz a figura dos conselhos gestores de políticas públicas como espaços fundamentais para a participação representativa $\mathrm{e}$ 
o exercício da cidadania (JACOBI, 2003). Porém, a efetivação

desse mecanismo não tem ocorrido da maneira desejada, já que atualmente o conselho encontra-se desmobilizado frente à expectativa frustrada com a abertura do parque e por este não ser um espaço habitual dessas comunidades.

Desde a iniciação dos programas ambientais na área de implantação da UHE Quebra Queixo, a população do entorno já demonstrou expectativas de uso e de visitação, um exemplo são as trilhas que os próprios moradores auxiliaram na construção (FATMA, 2007). Porém, percebe-se a insatisfação da população quanto à proibição do uso dessa área, pois o parque permanece fechado para visitação pública, até mesmo para os moradores locais, sendo aberto apenas para pesquisas científicas, o que gera o desinteresse por parte da população. Para diminuir a insatisfação dos moradores do entorno,é necessária a implantação de programas que melhorem a qualidade de vida dessas comunidades, por meio do aumento de fontes geradoras de renda para o entorno e que visem objetivos comuns.

\section{Da Percep̧ão Ambiental}

A percepção ambiental nem sempre é algo expresso ou verbalizado cotidianamente na vida das pessoas, mas isso não significa que ela não seja vivenciada. Entre o expressar, o verbalizar e o viver podem haver hiatos. No que se refere à categoria preservação, a palavra água recebeu um papel especial, conforme os depoimentos que seguem: "Olha, eu acho que hoje se já tem alguns problemas quem sabe que já foi lá atrás que não souberam preservar né, tem menos fonte de água, outras coisas né, então eu acho que é muito importante né"; "É preservar a natureza, os animais em extinção[...]; "[...] precisaria, eu acho, que mais cuidado e coisa é a água, eu acho bastante a água.".

Para os moradores locais, os recursos hídricos devem ser mais preservados. Eles afirmam, ainda, que procuram dar mais atenção à água. Segundo os entrevistados, o grande problema da poluição desses ambientes pode ser encontrado nos ambientes urbanos: "O agricultor é consciente, o problema está na cidade.”; “A cobrança é muito grande em cima do agricultor, mas nas cidades nada, o problema está lá, não está aqui [...]”.

Segundo Tuan (1980) cada ser humano percebe seu redor por meio de todos os seus sentidos e ao mesmo tempo, sendo assim, 
os seres humanos não observam o ambiente igualmente, mas partilham algumas percepções, como a visão, que frequentemente está diretamente ligada à cultura. Tuan (1980) ainda destaca que os seres humanos veem a natureza segmentada em objetos como árvores, pedras, animais, pertencentes a um fundo, como a água e o ar, geralmente organizados em oposições binárias, assim, a palavra preservação seria uma polaridade à palavra água para os entrevistados. "A água é uma imagem do inconsciente; ela é amorfa, mas fertilizadora, uma fonte potencial de força. A água simboliza o lado feminino da personalidade humana." (TUAN, 1980, p. 21). Assim, essas interpretações tornam-se um costume da vivência e consciência humana.

Além disso, o tema água torna-se assíduo em discursos e notícias, sendo frequentemente apresentado e discutido em diferentes meios de comunicação. Eventos que abordam o tema água, como o Dia Mundial da Água (22 de março) e a Semana Mundial da Água, criam oportunidades de transformação das obrigações para as ações. Também a Lei $n^{\circ}$ 9.985, de julho de 2000, que define o termo Unidade de Conservação, inclui as águas jurisdicionais com objetivos de conservação (SNUC, 2006). Em 2012, também houve a oficialização do Ano Internacional de Cooperação pela Água, pela Organização das Nações Unidas (ONU), que buscou o estímulo para o crescimento da cooperação na gestão dos recursos hídricos.

Acredita-se que a importância dada à água também possa estar relacionada com algumas crenças religiosas. Nas igrejas a água é muito mencionada pelos padres e pastores e, sendo este um local frequentado semanalmente pelos agricultor, é uma fonte de informação para eles. As religiões sempre tiveram uma relação simbólica com a água, isso é mostrado em textos sagrados ou em celebrações como o de batismo, representando o nascimento e a purificação. Além disso, a água representa, em primeiro lugar, a fonte da vida e a origem de todas as coisas.

São as mulheres, no âmbito doméstico, que se ressentem duplamente da escassez de água, seja aquela da lavoura, seja aquela para atender as demandas da casa, como asseio, cozinha etc. A agricultura é uma atividade que está intrinsicamente ligada à natureza. Uma boa safra depende de boas condições climáticas. De forma utilitarista, os agricultores, em suas trajetórias familiares, vivenciaram estiagem e guardam na memória o que representou 
para a economia do grupo familiar a falta ou excesso de água no ciclo agrícola, levando-os à privação.

\section{Da Unidade de Conservação}

Como o parque está fechado para a visitação, muitos moradores demostram desinteresse pelo andamento dos trabalhos, que iniciaram em janeiro de 2010 para a implantação de estruturas de uso público, mas que por problemas administrativos foram e continuam embargadas. A partir das entrevistas, constatou-se divergências dos moradores com a gestão da UC perante as leis e normas ambientais que proíbem algumas de suas atividades, como a caça, o desmatamento e a coleta de pinhão, que, segundo os entrevistados, não é devidamente esclarecido para a comunidade.

Sobre a Unidade de Conservação, seis do total de entrevistados já ouviram falar na palavra Unidade de Conservação e dez desconhecem o termo científico da palavra, muitas vezes, não fazendo a relação deste com o PEA, mesmo o conhecendo. Brito (2008), em estudo com percepção ambiental, destaca as dificuldades dos moradores em definir o que é uma Unidade de Conservação e quem é o órgão gestor dessa área natural protegida, sendo que muitos nem sabem da existência desta.

Segundo um senhor que pertence a uma das famílias que trabalhou na antiga serraria da Família Berthier, a profissão de extrair madeira era cultural, passada de uma geração para outra: "[...] vim de uma família de madeireiros, meu avô foi madeireiro, meu pai também, eu fui até os 30 anos mais ou menos e era o meio de sobrevivência, era o ciclo, vamos dizer ciclo do ouro, ciclo da cana, ciclo da madeira [...]". Seu avô teria iniciado com a exploração madeireira, seu pai também trabalhava na mesma área e ele mesmo havia colaborado com o corte de inúmeras araucárias nas terras que hoje são preservadas dentro de uma Unidade de Conservação.

A exploração madeireira foi um dos grandes problemas da região nas décadas de 1980 e 1990, onde a extração era principalmente de uma espécie que atualmente está em nível crítico de ameaça de extinção, o pinheiro araucária (Araucaria angustifolia). A araucária é tida como criticamente em perigo de extinção desde 2006, mas atualmente, com o aumento da conscientização e fiscalização, não é mais explorada, tornando possível diminuir alguns dos empecilhos para a conservação 
(FATMA, 2007). Porém, outro problema é o crescimento da monocultura de árvores exóticas como o pinus e eucalipto, pois a demanda por madeira em São Domingos é grande, sendo o seu principal uso associado à lenha, que normalmente é extraída, e não produzida (FATMA, 2007). A monocultura causa o isolamento dos fragmentos de florestas nativas existentes e eliminam as chances da Floresta Ombrófila Mista retomar as áreas desmatadas.

As ações preventivas e informativas cabem ao órgão gestor da unidade, assim como o subsídio às propostas de criação da unidade e regimentos em consonância com o previsto no plano de manejo e legislação ambiental relacionada. Porém, as afirmações, segundo os moradores, dizem que a fiscalização é dada somente com a aplicação de penalidades, com multas e, em alguns casos, até a prisão no caso de descumprimento da lei. Segundo Silva, Candido e Freire, (2009), essa tática de conservação tem falhado muito, sendo que os crimes ambientais continuam ocorrendo agressivamente em muitas outras áreas protegidas.

O mesmo morador que teve como ocupação profissional a exploração de madeira, trabalhou como vigilante do parque e participa de uma organização não governamental (ONG), o Grupo de Apoio à Gestão do Parque Estadual das Araucárias (Grimpeiro), que foi criado com o objetivo de apoiar e auxiliar a gestão do parque, além de representar peça importante no planejamento ambiental. Percebe-se que esse antigo madeireiro mudou sua percepção quanto ao ambiente em que vive: "[...] antigamente você não tinha a noção que tem hoje, essa área aqui são 600 e poucos hectares, a gente derrubou tudo e queimou pra fazer lavoura, não respeitando o rio, a nascente, tudo era terra, então foi feito tudo lavoura, hoje a consciência é bem maior, até pela lei, a lei exige hoje, então tem que preservar o rio [...]".

É possível notar a presença de um paradigma entre alguns moradores. Alguns deles tinham uma determinada visão sobre o ambiente ao seu redor, mas com a criação do parque sua percepção foi modificada. Ocorreram mudanças de emprego, o antigo madeireiro, por exemplo, foi vigilante do parque e agora representa uma ONG. Uma antiga professora que se tornou agricultora; um morador que trabalhava com fumo e decidiu mudar a forma de produção para diminuir o uso de agrotóxicos na propriedade: “[...] hoje é o inverso, eu sempre digo, todo ser humano tinha que se redimir do pecado para ir para o céu, agora estou me redimindo, 
o que eu derrubei de árvore hoje eu estou plantando, então tem que redimir $[\ldots]$ ".

De acordo com Tuan (1980), para compreender a percepção ambiental de uma pessoa é necessário explorar a sua herança biológica, cultural, sua história, sua criação e as experiências vividas no ambiente físico, pois os conceitos culturais e ambientais são princípios que se sobrepõe e estes podem condicionar os valores ambientais e a percepção do ser humano. Assim, à medida que a cultura e a sociedade evoluem, o comportamento em relação ao meio ambiente também se modifica, podendo inverter-se.

\section{Da Educação Ambiental}

A Educação Ambiental tornou-se um caminho essencial à sustentabilidade, assim como à qualidade de vida (VASCONCELLOS, 2006). Entretanto, no Brasil, os programas de Educação Ambiental em áreas protegidas são fracos, pois o entorno dessas áreas precisa estar mais adequado e aliado aos objetivos da conservação da natureza (LOUREIRO; CUNHA, 2008). As Unidades de Conservação que proporcionam o uso público facilitam às pessoas o acesso individual e coletivo à natureza por meio de programas de Educação Ambiental, o que representa um direito de todos e é onde todos são educadores e aprendizes.

A Educação Ambiental tem a intensão de enfocar a relação entre o ser humano e o universo de uma forma mais interdisciplinar, assim como formar cidadãos com consciência ambiental, social, cultural e ecológica (VASCONCELLOS, 2006). A partir daí, ações coletivas e processos de construção de valores sociais e culturais ganharam mais espaço. Um grande avanço na área de Educação Ambiental deu-se pela aprovação da Lei n ${ }^{\circ}$ 9.795, de 27 de abril de 1999, que instituiu a Política Nacional de Educação Ambiental (BRASIL, 1999).

O Parque Estadual das Araucárias dispõe, em seu plano de manejo, de um Programa de Visitação composto pelo Subprograma de Interpretação e Educação Ambiental e Subprograma de Recreação, os quais representam grande potencial para a Educação Ambiental e recreação voltada à Mata de Araucária e sua biodiversidade, visando principalmente a conscientização ambiental dos moradores do entorno. De acordo com os dados da pesquisa, os moradores auxiliaram na construção de trilhas dentro da unidade, que devem ser usadas para ações 
de Educação Ambiental, o que demonstra o interesse da parte deles para a realização dessas atividades e a implantação de parte das ações previstas nesses subprogramas. Porém, como o parque ainda não foi aberto para visitação, as trilhas foram esquecidas e o envolvimento desses moradores diminuiu.

Um dos grandes problemas quanto ao embate entre gestão e comunidades são as políticas públicas de conservação ambiental (GUSSONATO; BARBOSA; SUZUKI, 2010). Grande parte dessas políticas tem índole de repressão, onde os métodos utilizados são a fiscalização e a punição, por serem baseadas na ideia de Unidades de Conservação isoladas de seres humanos. Isso demonstra a importância da Educação Ambiental, que trabalha de uma forma consciente, e não que impõe regras. Dessa forma, é possível construir a conscientização ambiental dessas comunidades, para que elas mostrem seus potenciais conservadores.

Em Unidades de Conservação, as trilhas devem ser planejadas de acordo com os objetivos do programa interpretativo previsto no plano de manejo da unidade, e para que sejam cumpridos esses objetivos é necessário envolver todas as pessoas interessadas (RIBEIRO; LOBATO; LIBERATO; 2009). A utilização de trilhas interpretativas tem crescido muito pelos que querem ter mais contato com a natureza, e a participação em geral das comunidades locais é a chave para o sucesso dos programas de conservação e manejo, especialmente fora das Unidades de Conservação.

Atividades como as hortas pedagógicas, geralmente realizadas com crianças em escolas próximas as UCs, também sempre trazem bons resultados por meio da experiência direta e pessoal e do conhecimento adquirido (LUCENA, 2010). As crianças desenvolvem melhor os conceitos e criam maneiras diferentes de pensar na hora de tomar decisões relacionadas com o meio ambiente e os seres vivos. Além disso, é necessário destacar a importância desse tipo de projeto para ensinar ao aluno a significância prática da conservação, do respeito para com o meio ambiente e praticar a Educação Ambiental com mais convivência com a natureza.

\section{Considerações finais}

Longo é o caminho para vencer as dificuldades na gestão de Unidades de Conservação, principalmente com relação à falta 
de envolvimento, de interesse e de informação das comunidades locais, o que dificulta os processos de gestão participativa e, consequentemente, o manejo e a conservação. Um elemento fundamental para que haja o envolvimento e a participação das comunidades locais são ações realizadas pelas instituições de conservação, que contribuem com as necessidades da população. Muitas vezes, as necessidades são básicas, como assistência técnica, infraestrutura, saúde, educação, entre outras. Segundo Soares, Bensusan e Ferreira Neto (2004), as instituições que garantem assistência técnica aos produtores e que buscam fontes geradoras de renda têm conseguido maior envolvimento e participação do público na construção de propostas para a conservação dessas áreas protegidas.

É de grande importância compreender como os residentes locais interagem e percebem o ambiente em que estão inseridos, assim como os problemas por eles destacados, para que, dessa forma, a relação entre os moradores e gestores de uma Unidade de Conservação fique mais próxima e fortalecida. Além disso, essa compreensão auxilia na elaboração e implementação de programas de comunicação, assim como os programas de Educação Ambiental para a conscientização.

O conselho consultivo do Parque Estadual das Araucárias representa uma boa iniciativa, pois fortalece a relação entre os envolvidos, porém, a população está desmobilizada e faltam o incentivo e a comunicação, que são os principais aliados da conservação. Também falta o envolvimento de ONGs, como o Grimpeiro no PEA, nos órgãos ambientais e nos instituições de pesquisa, como a Unochapecó, os quais podem executar seus papeis ambientais nas UCs, levando informação e boas práticas de manejo.

Os dados da pesquisa representam a situação de muitas outras UCs do Brasil, onde há muita falta de comunicação entre autoridades e moradores, obras paralisadas, pouca informação e promessas não cumpridas. Apesar da carência de programas de Educação Ambiental em Unidades de Conservação, o PEA mostrou-se com grande potencial para várias propostas educativas no processo de gestão ambiental, além disso, percebe-se que a população aprova a criação do parque e com certeza apoiaria às ações de conservação se lhes forem propostas e postas em prática.

Para que os objetivos das Unidades de Conservação sejam alcançados, é necessário irmos além do entendimento de seu 
significado ou função socioambiental, mas também criar espaços de diálogo entre gestores, comunidades locais, instituições e todos os interessados em alcançar o desenvolvimento sustentável e a conservação ambiental. Não basta apenas investir em fiscalização e não movimentar as práticas sustentáveis aliadas ao desenvolvimento social e humano e à Educação Ambiental.

Segundo Primack et al. (2006), os programas de conservação também devem estar voltados à ecologia urbana, pois a maior parte da população está concentrada nos ambientes urbanos, assim, esses projetos podem dar uma dimensão maior aos impactos do consumo humano. A consciência, não só nas áreas urbanas, favorece também a vida silvestre, como o cultivo de espécies vegetais em edifícios, a plantação de árvores frutíferas em quintais urbanos, a construção de parques e a manutenção de jardins.

O desenvolvimento sustentável está ligado ao uso dos ecossistemas naturais, mas também à manutenção da qualidade da biodiversidade e isso depende do planejamento comunitário participativo, estes devem funcionar de uma forma interessante para que as pessoas eduquem-se sem perceber e compreendam de modo simples a dimensão dos objetivos da conservação.

Dentro disso, a capacitação de todos os que trabalham nas Unidades de Conservação é um componente essencial que possibilita vencer a realidade política onde o patrimônio natural da humanidade não é prioridade, assim como minimizar os conflitos entre os moradores e a gestão. Além disso, os gestores devem estar sempre atentos às novas técnicas, estratégias e recursos que fortaleçam a gestão dessas áreas, buscando sempre a parceria entre as populações e autoridades locais, assim todos se beneficiaram.

No que diz respeito à garantia de conservação dos ecossistemas e do habitat, a criação e implantação de Unidades de Conservação de proteção integral são as mais apontadas em termos de qualificação e tamanho. As unidades de uso sustentável devem assegurar uma proteção complementar, conectando-se às áreas integralmente protegidas e atendendo aos interesses presentes e futuros da sociedade.

\section{Referências}

ALBUQUERQUE, Ulysses P.; LUCENA, Reinaldo F. P.; ALENCAR, Nélson L. Métodos e Técnicas para coleta de dados etnobiológicos. In: Métodos e Técnicas na pesquisa Etnobiológica e Etnoecológica. vol 1. Recife: Nuppea, 2010. 
ALEXÍADES, M. N. Collecting ethnobotanical data: an introduction to basic concepts andtechniques. In: ALEXIADES, M. N. Guidelines for ethnobotanical field collectors. New York: The New York Botanical Garden, 1996. p. 53-94.

APREMAVI, Associação de Preservação do Meio Ambiente e da Vida. Gestão participativa em Unidades de Conservação: uma experiência na Mata Atlântica. 1 ed. Rio do Sul -SC, 2012.

BRESOLIN, Alan José; ZAKRZEVSKI, Sônia Beatriz Balvedi ; MARINHO, Jorge Reppold. Percepção, Comunicação e Educação Ambiental em Unidades de Conservação: Um Estudo no Parque Estadual Espigão Alto - Barracão/RS - Brasil. Erechim, 2010.

BRASIL. Política Nacional de Educação Ambiental. Brasília: Ministério do Meio Ambiente/ MEC, 1999.

BRITO, Daguinete Maria Chaves. Conflitos em Unidades de Conservação. Revista de Humanidades do Curso de Ciências Sociais. UNIFAP, 2008.

CAPANEMA. Prefeitura Municipal de Capanema. Notícias. Capanema: abr/2013. Disponível em: http://www.capanema.pr.gov.br/ noticias.php. Acesso em: 04/ago/2014.

CARNEIRO, Maria J.; CASTRO, Elisa G. Juventude Rural em perspectiva. Rio de Janeiro: Mauad X, 2007.

DIEGUES, Antônio Carlos. O mito moderno da natureza intocada. Editora Hucitec. São Paulo, 2001.

DRUMMOND, José; FRANCO, José L. de Andrade; OLIVEIRA, Daniela. Uma análise sobre a História e a Situação das Unidades de Conservação no Brasil. Conservação da Biodiversidade: Legislação e Políticas Públicas. Brasília-DF, 2011.

DRUMOND, Maria Auxiliadora. Participação Comunitária no Manejo de Unidades de Conservação: Manual de Técnicas e Ferramentas. Belo Horizonte, 2002.

FATMA, Fundação do Meio Ambiente. Plano de Manejo para o Parque Estadual das Araucárias. Florianópolis: FATMA, 2007. Disponível em: http://www.fatma.sc.gov.br/index.php?option=com_ content\&task=view\&id=81\&Itemid=159. Acesso em: 04 ago. 2014. 
GUSSONATO, Leon; BARBOSA, Talita dos Santos; SUZUKI, Júlio Cézar. Divergências Conceituais nas Políticas Públicas de Conservação Ambiental: o caso da Comunidade de Peropava. In: ENCONTRO NACIONAL DOS GEÓGRAFOS. Porto Alegre. Anais. Porto Alegre, 2010.

IBGE, Instituto Brasileiro do Meio Ambiente e dos Recursos Renováveis. IBGE Cidades. Santa Catarina. Galvão. 2010. Disponível em: <http://www.ibge.gov.br/cidadesat/>. Acesso em: 16 ago. 2014.

JACOBI, Pedro Roberto. Espaços Públicos e Práticas Participativas na Gestão do Meio Ambiente do Brasil. Sociedade e Estado. Brasília, v. 18, n 1/2, p. 315-338, jan./dez. 2003.

LOUREIRO, Carlos Frederico Bernardo; CUNHA, Cláudia Conceição. Educação Ambiental e Gestão Participativa de Unidades de Conservação: Elementos para se pensar na Sustentabilidade Democrática. Ambiente e Sociedade. Campinas, 2008.

LUCENA, Mycarla Míria Araujo de. Percepção ambiental por uma comunidaderural do entorno de uma Reserva ParticulardoPatrimônio Natural (RPPN), semiárido brasileiro. Dissertação (Mestrado) Programa Regional de Pós-Graduação em Desenvolvimento e Meio Ambiente, Universidade Federal do Rio Grande do Norte, 2010.

MEDEIROS, Rodrigo, et al. Contribuição das Unidades de Conservação Brasileiras para a Economia Nacional: Sumário Executivo. Brasília: UNEP-WCMC, 2011.

MEDEIROS, Rodrigo; IRVING, Marta; GARAY, Irene. A Proteção da Natureza no Brasil: Evolução e Conflitos de um Modelo em Construção. Salvador - Bahia, 2004.

NASCIMENTO, Daniel T.; BRUSZTYN, Maria A.A. Análise de conflitos socioambientais: o caso da comunidade rural de rio maior, município de Urussanga, Santa Catarina. Revista internacional interdisciplinar INTERthesis. Florianópolis, v. 09, n.2, jul/dez. 2012.

PONTY, Maurice Merleau. Fenomenologia da Percepção. São Paulo: 1999.

PRIMACK, Richard, et al. Conservación fuera de las áreas protegidas. Fondo de Cultura Económica; jan/2006.

RIBEIRO, Carvalho Wallace; LOBATO, Wolney; LIBERATO, Rita 
de Cássia. Notas sobre fenomenologia, percepção e educação ambiental.

Sinapse ambiental. set/2009.

RYLANDS, Anthony B.; BRANDON, Katrina. Unidades de Conservação Brasileiras. 2005.

SILVA, Thaise Souza da; CANDIDO, Gesinaldo Ataíde; FREIRE, Eliza Maria Xavier. Conceitos, Percepções e Estratégias para a Conservação de uma Estação Ecológica da Caatinga Nordestina por Populações de seu entorno. Sociedade e Natureza, Uberlândia, 2009.

SOARES, Maria Clara Couto; BENSUSAN, Nurit; FERREIRA NETO, Paulo Sérgio. Entorno de Unidades de Conservação: Estudo de Experiências com UCs de Proteção Integral. Rio de Janeiro, 2004.

SOSMA - Fundação SOS. Mata Atlântica. Disponível em: <http;// mapas.sosma.org.br.

SNUC, Sistema Nacional de Unidades de Conservação da Natureza. Lei no 9.985, 18 de julho de 2000; decreto no 4.340, de 22 de agosto de 2002. 6. ed. Brasília: MMA 2006.

TUAN, Yi-Fu. Topofilia: um estudo da percepção, atitudes e valores do meio ambiente. São Paulo: Difel, 1980.

VASCONCELLOS, Jane M. de O. Educação e Interpretação Ambiental em Unidades de Conservação. Fundação $O$ Boticário de Proteção à Natureza. Cadernos de Conservação. Curitiba/PR. Ano 03. n. 04. Dez/2006.

ZAÚ, André Scarambone. Áreas Especiais no Estado de Santa Catarina. 1998. 


\title{
ENVIRONMENTAL PERCEPTION INTHE VICINITY OF CONSERVATION AREA PARQUE ESTADUAL DAS ARAUCÁRIAS
}

\begin{abstract}
This article purpose is to raise the environmental perception from people who live next to a Conservation Unit in the West of Santa Catarina State, the Parque Estadual das Araucárias, as well as understand the main problems that affect them, in addition to highlighting the importance of the participation of these residents, as a tool for biodiversity conservation. In addition, also sought to identify the positive and negative aspects to the Conservation Unit is to these communities so that from this, some actions may be directed to environmental education and new environmental conservation programs are implemented. The data from the Conservation Unit and the environmental were analyzed searching for tools that can be applied on the Parque Estadual das Araucárias conservation and its management and planning. The Conservation Unit is localized between the cities of Galvão and São Domingos, at Chapecó River basin. In this study, were realized 16 interview at six distinct communities. Six people said that heard about the Conservation Unit, six heard about Conservation Unit, and for 10 people, the scientific mean of the word is unknown. Few of the interviewee know how to define what environmental is, always being acquainted with preservation. The survey data represents the delicate situation of UC, and we need to understand how these local communities perceive the environmental where they live, such as the problems of these communities. These analyses can be used to make the relation between these local communities and the Conservation Unit objectives stronger and effective.
\end{abstract}

Keywords: Protected area. Damping zone. Environmental perception. 